\title{
Review of Chinese English Learners' Prosodic Acquisition
}

\author{
Yan $\mathrm{Wu}^{1}$ \\ ${ }^{1}$ School of English Language, North China Electric Power University, Baoding, China \\ Correspondence: Yan Wu, School of English Language, North China Electric Power University, Baoding, \\ China.
}

Received: May 13, 2019 Accepted: July 16, 2019 Online Published: July 18, 2019

doi: 10.5539/elt.v12n8p89 URL: https://doi.org/10.5539/elt.v12n8p89

\begin{abstract}
The traditional focus of English phonetic teaching in China has consistently been on the segmental acquisition, which is mainly highlighting the pronunciation of vowels and consonants, while its suprasegmental knowledge in speech naturalness, coherence and understanding is relatively insufficient. In addition, Chinese students have a serious problem in the rhythm of English language, which is mainly influenced by the characteristics of the syllable-timed in their mother tongue rather than in a stress-timed way. This study reviews the academic works of the nearly 15 years in the development of Chinese prosodic features of English language, giving a better and deeper analysis and appreciation of the suprasegmental phoneme levels of different aspects, such as the fundamental components of English prosody such as stress, rhythm and intonation. This study is hoped to shed light on the prosodic analysis of Chinese English learners' oral proficiency in pronunciation, finding out the insufficiency in prosody of China English, and more importantly to provide effective learning strategy for Chinese English learners and teachers in prosody acquisition, therefore, it might pave the way to the reform of oral English teaching in China.
\end{abstract}

Keywords: China English, English prosodic feature, prosodic acquisition

\section{Introduction}

\subsection{China English in Prosodic Acquisition}

With the booming of globalization, English, as a commonly universal language, has been developed into multiple localized "English" languages, including "China English", as a naturally occurrence of English language learning. The concept initially proposed by Li (1993) points out that "China English" is based on the standard English as the core, to express the unique ideas in Chinese social and cultural areas, free from being affected by its mother tongue interference. Through various means of English communication, such as transliteration, discussion and semantic regeneration, it particularly features in its distinctive Chinese elements in vocabulary, sentence and discourse. When it comes to the phonetic aspect, the unique "China English" is primarily embodied in the suprasegmental features.

Most English learners, including college students, who have been learnt English reading, writing and grammar for more than ten years, still have serious problems in oral communication, finding themselves labeled as "China English" or "foreign accent" to the native speakers ( $\mathrm{Li}, 2019)$.

\subsection{Importance of Prosodic Acquisition}

With respect to the review of English prosody acquisition, this study is aimed to find out some effective teaching activities to improve Chinese English language learners' prosodic level, reducing the negative transfer of Chinglish. It can also help teachers understand the use of communicative prosody of learners, and design the teaching of communicative prosody in a targeted way, so as to effectively improve learners' oral communication level.

Compared with written language, oral communication carries more vivid and richer implications in real life performance, which not only delivers the messages but also conveys some hidden cues with the variations in speakers' pitch or rhythmic patterns in different contexts. For instance, stress in words and sentences sound less natural when Chinese English learners speak English, wrongly or randomly placing the stress or pitch in their speech.

Practically, as an increasingly indispensable component in assessing English learners' comprehensive capability 
of spoken English, prosodic analysis has gained a growing attention among educators and learners. Due to the fact that English and Chinese are categorized into two different language systems, with their sound structure and rhythm patterns being quite different, it is understandably challenging for Chinese English learners to acquire prosodic features and employ stress, rhythm and intonation patterns in their speech to make themselves easy to be understood (Calet, Simpson, \& Defior, 2015). This does not only occur to Chinese students, but also to English teachers in schools, ranging from elementary schools to high educational institutions, because in most test-oriented educational background, the prosodic features seem to go unnoticed in written language teaching and acquisition.

\section{International Research on the Prosodic Features}

Prosody, as a term used in suprasegmental phonetics and phonology, refers to the variations in pitch, loudness, tempo and rhythm (Crystal, 2008), which is widely employed to reflect the components of language in terms of its acoustic and rhythmic effects. There has been an upward tendency in recognition of its cardinal significance in oral speech in recent years, and it manifests the features of groups of syllables, words and phrases, such as thought groups in speech, with variations in stress, rhythm, intonation, reduction and assimilation or liaisons, all of which would shape the feature of English quite distinct from China English, thus helping it be easily understood or comprehended by native speakers.

\subsection{Stress}

Stress is referred to loudness, length, and higher pitch of individual syllables (Roach, 2009). It represents the extra strength or energy when delivering syllables in English, describing the varied positions of pitch in a word or sentences, or it can be simply referred to the duration of the lengthened vowel with amplified volume.

Native speakers, more often relying on the stress and rhythm, tell the meaning in real life communication by conveying the feeling or message in stress. For instance, the shift of meaning in the following sentences can be achieved with the change of its stress location.

(a) Seyit lost the PUPPY yesterday?

(b) SEYIT lost the puppy yesterday?

In (a), the speaker placed the stress on the word of "puppy", exhibiting his doubt on the puppy he lost, while in (b) the stress shifts to "Seyit" which means the speaker is surprised that Seyit, rather than anyone else, got the baby dog lost.

In addition, English is a non-tone language, so speakers can only depend on stress to express the minute changes in tones and meaning.

\subsection{Rhythm}

Rhythm refers to the perceived regularity of prominent units in speech (Crystal, 2008). English, as a stress-timed language, is timed by the syllables we stress, and it is irregular in rhythm, which means syllables constitutes the basis of the rhythmic beat and individual syllables tend to be more evenly timed, while Chinese is the typical syllable-timed language.

\subsection{Intonation}

Intonation refers to pitch patterns in spoken English to convey strong thoughts and varied feelings, which is shown in acoustic features such as pitch, intensity, duration, pause, loudness, speech rate and voice quality (Cruttenden, 2001). Intonation can be understood as the grammar of speech, expressing the hidden feelings or meaning with the variations of rising and falling pitch, displaying the musicality of the language. Meanwhile, it can be also seen to tell the hearers whether the speaker has finished his sentence or not with falling tone or rising tone. Sometimes with the change of tones, topic can be shifted with the pitch range of the beginning of a sentence on the rise.

Recently, most Chinese English learners' spoken level vary with different accents, but generally carrying strong isolated segmental characteristics due to the lack of prosodic feature training.

In stress, China English sounds shorter in terms of duration of vowel in stressed syllables compared with the native speakers, while spend more time on uttering consonants than vowel in stressed syllables. Meanwhile, Chinese English learners tend to distribute the same duration to stressed and distressed syllables with no difference in between. Moreover, no variation in pitch in stressed syllables, making China English to be a typical monotone, unnatural, robotic English. In rhythm and intonation, mainly affected by mother tongue, Chinese students often fail to notice the differences of stress-timed English language, or even wrongly stress the wrong 
syllables, making the speech sound perplexing and confusing.

\subsection{Prosody Features}

With the big picture of how fundamental components of prosody features of spoken English, we can easily come to the more explicit table with major features illustrated as below:

Table 1. Prosody in English in terms of phonological structure

\begin{tabular}{|c|c|c|}
\hline \multicolumn{3}{|c|}{ Stress, Rhythm and Intonation in Phonological Structure } \\
\hline & stress type & $\begin{array}{l}\text { lexical stress } \\
\text { sentence stress }\end{array}$ \\
\hline \multirow[t]{3}{*}{ Stress } & & adding rhythm to sentences \\
\hline & function & $\begin{array}{l}\text { producing rhythmic unit in sentences } \\
\text { stress-timed }\end{array}$ \\
\hline & rhythm & syllable-timed \\
\hline \multirow[t]{5}{*}{ Rhythm } & type & mora-timed \\
\hline & & adding peaks and valleys to sentences \\
\hline & function & $\begin{array}{l}\text { producing variation in strength and speed } \\
\text { falling tone }\end{array}$ \\
\hline & intonation & rising tone \\
\hline & type & falling-rising tone \\
\hline \multirow[t]{3}{*}{ Intonation } & & rising-falling tone \\
\hline & & conveying feelings \\
\hline & function & exchanging information \\
\hline
\end{tabular}

\section{National Research on the Prosodic Features}

In linguistics, the major task of English teaching on phonological acquisition is more focused on segmental knowledge, providing the English learners with wide access to certain courses in pronunciation acquisition in China, which absolutely facilitate the grasp of most segmental phoneme skills and techniques. Of course, due to the negative migration interference of the native language, it takes an extra effort to master some errant phonemes. Particularly, the sound of some diphthongs and short vowels in English is a place where many students have to pay more attention to and needs to be improved. Most of the English major students spend years on segmental knowledge acquisition, which mainly focuses on pronunciation of single vowels and consonants as well as the acquisition of consonants and liaison such as swallowing the sound, and have achieved a considerable effect (Wen, 2008). During the past decade, there have been an abundance of research conducted in this area, and the segmental teaching materials on the market outnumber the super segmental ones, which can signify the presence of disparity of its importance English language research.

In terms of prosodic acquisition, the recent decade has also seen a gradual increase of research emphasis, with the majority of exploration into the prosodic features of stress shift, rhythm patterns, tone awareness, and metrical pattern of the indicators of learners in English reading and so on. One of the outstanding researchers, Chen Ye, has conducted a systematic study on the intonation, stress repetition, rhythm and classification of the system. With the technological assistance of Ramus delta and $\% \mathrm{~V}$ research methods by means of experimental phonetics, her research, mainly reveals the change trend of tone mode, finding that Chinese English learners are mainly possessed with a negative increasing trend mode in intonation with too much falling tone. Learners fail to realize the important role of phonetics in the semantic study (Chen \& Wang, 2015).

Follow-up studies include time rate effect in prosodic features acquisition, incorporating the frequency effect research conducted from the metrical structure division, accent and pitch movement aspects, and finding that the input frequency is of more significant influence on student metrical structure of acquisition compared with the output frequency; there is no significant difference between the input and output frequencies on the stress and tone; the learners have difficulty in learning about the focus of the information and the phrases in the end of the 
sentences, as well as the time/place adverbials at the end of the sentences. The study also illustrates the need to strengthen the explicit guidance of the rhythm of the English language to train the cadence of the students. In 2015, Chen and Wang also studied the stress characteristics of the phrase in English. With the help of speech corpus, they did massive experiment and study on dynamic and prepositional types of phrases, such as analyzing the stress characteristics of the study. What they have found is that there are many stress phenomena, especially the over-stress of the grammatical items. Therefore, they put forward the phrase stress as a necessity of explicit instruction in teaching and textbooks in China.

In addition, Wang (2013) has done some research on foreign prosoidic feature acquisition, in comparision with Chinese students language learning through English reading of non-English major students, discovering that there is a close correlation between the lack of intonation phrase markers and the failure of intonation phrase division, restricted by speech style and online production management. Meanwhile, Zhang (2017) from the three prosodic features (meaning group, language group of highlights and non- highlight) examined the rhythm pattern of discourse marker, while Xia and $\mathrm{Mu}$ (2008) also found that English learners are comparatively weaker in ability in border implied topic shift than English native speakers.

At the same time, from the perspective of negative transfer of mother tongue, the researchers examined how stress and intonation of Chinese language influenced English phonetic acquisition the from the supra segmental level, Chinese English language learners are prone to have rear stress in English vocabulary and have the tendency to stress on the second syllable, due to the unconscious influence of Chinese double syllable words' "rear stress".

\section{Problems and Thoughts That Exist}

Currently, the nationwide suprasegmental feature acquisition research, mainly concentrates on the reading of corpus analysis. Having experienced a long process in prosodic analysis, the research methods and approaches of the study have dramatically improved with hierarchy and the improved level has been noticeable in all over the country (Abercrombie, 1967). However, in addition to the diachronic study, today's study on prosodic feature is mainly characterized with the corpus-based study, experimental analysis, comparative analysis of multiple features.

The existing problems are obvious, despite the remarkable achievements we have gained in recent decades in the study of phonology. In almost 20 years, researchers are more concentrated on the findings of second language speech acquisition, with the assistance of corpus analysis from all the parameter characteristics of prosodic features, while the dynamic study of teaching rhythm acquisition appearing inadequate; ranging from the strategy research of metrical acquisition to how to overcome the negative transfer of mother tongue and to acquire English rhythm, all of which seem to be far from inadequate (Rosenberg \& Hirschberg, 2010). Therefore, the work of promoting real dynamic research on second language prosodic features acquisition seems to be inevitable and should be implemented immediately.

Additionally, the research methods also need to be improved and updated further. First, case study and the study of the longitudinal study are relatively small in quantity and low in quality, so it results in the some related difficulty in explanation of prosodic acquisition and development in an effective way. Second, despite the fact that experimental phonetics research methods and corpus linguistics research methods recently became popular, it is still limited in certain research phase, and requires to be implemented in a large scale, such as with the help of the use of a variety of voice software (researched Analyzer, Praat, ToBI, etc.), it can make speech visualized for every individual language learner. Additionally, The rhythm of the recessive characteristics acquisition such as BetterAccent Tutor voice software can make the implicit knowledge to be more explicit, strengthening learners' the intuitive understanding of supra segmental acquisition, but this demands a multitude of mixed ways of research to verify the performance and to give more scientific explanation to the second language rhythm acquisition (Frances \& Marianna, 2018). Last but not least, the majority of the research analysis is based on corpora for reading materials instead of being on the listener-oriented and more natural materials, in which readers are not natural and far from the autonomous discourse with the natural rhythm, therefore, expanding the scope of the corpora research really deserves further study and numerous hard work.

\section{Strategies for Teaching English Prosody}

Having learnt the current prosodic teaching insufficiency in China, some efficient and effective teaching activities are the introduced, closed accompanied with the main prosodic features (stress, rhythm \& intonation).

\subsection{Theoretical Training}

With the theoretical knowledge of prosody, students are more likely to develop their suprasegmental production 
and perception in spoken English, and with an abundance of practice and effort, learners are expected to shadow speaking on day-to-day basis by following and imitating native speakers from different ways, like with the digital help or real life pair or group work. Gradually, they can cultivate the growing sense of awareness of stress and distress, rhythm, intonation and other prosodic features in oral communication with the immersed authentic materials.

Chinese English learners can develop their awareness to divide the sentences into various thought groups accordingly, then focus on the stressed words and syllables which commonly carry more content meanings, such as nouns, adjectives, verbs and so forth. Among the content words, the primary stress and second stress are dropped on the particular syllables and it is noticed that the loudest syllables with the prominent peak should be considered as the core of the thought group when delivered.

It is necessary for Chinese English learners to participate more in the prosodic material activities, with a purpose of reducing the vowels in unstressed syllables and developing the habit of authentic rhythm of English as native speakers. Though imitation and repetition in reading, students can enjoy and learn to speak as natives. Meanwhile, musical materials can also be a great help for prosody learning due to their great similarity in the internal relation with one another, ranging from Jazz and chants to poems and jokes, all of which are taken as effective ways to practice and improve for English fluency (Timo, Tim, \& Jennifer, 2019). This may explain why students who are talented in music tend to show an edge in terms of English prosodic performance with better sense of rhythm of music and rhythm of language. In addition, more exposure to videos of English programs, such as some live radio programs, BBC, VOA on the internet or apps can also facilitate students' acquisition of prosodic features and performance by shadowing and imitating intonation.

In addition to enhancement of students' awareness of English prosody, teachers also need to raise their awareness in distinguishing the difference between Chinese and English languages. The application of Chinese sound rules into English language learning can only disrupt and interfere with the real English prosody acquisition. The ignorance of intonation in spoken English and the interference of their mother tongue in terms of intonation and sentence stress can really affect the meaning of the speech, even changing speaker's intention or attitude in oral communication (William, Tong, \& Kate, 2016). Tonicity makes Chinese students sometimes accent the wrong syllables or on the unstressed words. Therefore, in order to improve their falling-tone intonation and inaccurate delivery of speech in prosody need great efforts in different levels of English learning in China.

\subsection{Visual Aid}

In order to visualize this intangible learning process, making it easier for English learners to acquire the distinctive features in speech from the written language, some vivid pictures and drawings can be utilized to show the variations in prosody, facilitating students to form a much more concrete idea of prosodic acquisition. Therefore, learners can consciously divide the whole oral sentences into several individual thought groups according to the meaning, in each of which they can spot out the content words and function words with different musicality in speech.

Visualization of the prosodic features can help learners to develop the awareness of perception of intonation to improve their understanding of the prosody both at sentences and discourse level. By reading aloud the prosodic material and distress the unstressed syllables, English learners can gradually form the right way of speaking English with more appropriate prosodic features.

\subsection{Computer-Assisted Software}

In the information age, English learners have wide and easy access to a variety of software applications to facilitate their acquisition, and it is also true with the prosodic acquisition. One of the common available speech-visualization computer tools which is quite prevalent in language learning can be utilized contextually. Generally, the well-known application of Praat for the teaching and learning phonology, both for segmental and suprasegmental pronunciation, is quite effective and widely accepted in the circle.

\section{Summary}

In order to sound more like natives, fundamental prosodic features play a cardinal significant role in oral English, while the China English with the monotone can easily reveal our identity and even affect the accuracy of oral communication. Phonetics, as a branch of linguistics, should be taken as the core, expand to the periphery, and conduct research with other branches of linguistics (such as syntax, pragmatics), or should be applied through more interdisciplinary research with various branches of linguistics (such as psycholinguistics and cognitive linguistics).

All in all in order to improve their prosodic ability in English, students are encouraged to speak stressed syllable 
louder, higher and longer, especially in stressed vowel sounds, and to pause between thought groups to be stess-timed and to vary their tones in a more vivid way rather than to be monotone.

\section{Acknowledgement}

This research is financially supported by the Fundamental Research Funds for Central University of North China Electric Power University (2016MS139).

\section{References}

Abercrombie, D. (1967). Elements of general phonetics. Edinburgh, Edinburgh University Press.

Chen, Y. (2008). Study of the patterns of intonation of Chinese students. Shanghai, Shanghai Foreign Language.

Chen, Y., \& Wang, X. M. (2015). The study of the stress characteristics of Chinese students in English. Foreign Language and Foreign Language Teaching, 3, 13-18.

Calet, G. P., Simpson, G. T., \& Defior. (2015). Suprasegmental phonology development and reading acquisition: A longitudinal study. Scientific Studies of Reading, 19(1). https://doi.org/10.1080/10888438.2014.976342

Cruttenden, A. (2001). Gimson's Pronunciation of English (6th ed.). London, England: Edward Arnold Publishers Limited.

Crystal, D. (2008). .A Dictionary of Linguistics and Phonetics (6th ed.). Oxford, England: Blackwell Publishing. https://doi.org/10.1002/9781444302776

Frances B. \& Marianna N. (2018). Prosody and the meanings of English negative indefinites. Journal of Pragmatics, 129. https://doi.org/10.1016/j.pragma.2018.03.020

Li, W. Z. (1993). China English and Chinglish. Foreign Language Teaching and Research, 4, 18-24.

Li, X.H. (2019). The influence of mother tongue negative transfer on the oral English learning of senior college English majors and solutions. Journal of Aba Teahcers University, 36(2), 124-128.

Timo, B. R., Tim, M \& Jennifer, C. (2019). Mapping prosody onto meaning - the case of information structure in American English. Language, Cognition and Neuroscience, 34(7). https://doi.org/10.1080/ 23273798.2019.1587482

Roach, P. (2009). English Phonetics and Phonology: A Practical Course (4th ed.) Cambridge, Cambridge University Press.

Rosenberg, A., \& Hirschberg, J. (2010). Production of English prominence by native mandarin Chinese speakers. New York, NY: Queens College, CUNY; New York, NY: Columbia University.

Wang, J. (2013). Latest overseas developments in the study of prosody and some reflections. Journal of Foreign Languages, 6, 18-26.

Wen, Q. F. (2006). The trend and characteristics of English majors in English majors. Foreign Language Teaching and Research, 3, 189-195.

William, C., Tong, X. L., \& Kate C. (2016). Lexical prosody beyond first-language boundary: Chinese lexical tone sensitivity predicts English reading comprehension. Journal of Experimental Child Psychology, 148. https://doi.org/10.1016/j.jecp.2016.04.002

Xia, Z. H., \& Mu, F. Y. (2008). A study of boundary tone use at turn-taking in Chinese EFL learners' conversations. Journal of PLA Univeristy of Foreign Languages, 1, 48-54.

Zhang, Y. (2017). A review of prosody-pragmatics interface studies. Foreign Languages in China, 1, 104-111.

\section{Copyrights}

Copyright for this article is retained by the author(s), with first publication rights granted to the journal.

This is an open-access article distributed under the terms and conditions of the Creative Commons Attribution license (http://creativecommons.org/licenses/by/4.0/). 